Received: 17.11.2020; Revised: 30.12.2020; Accepted: 30.12.2020; Published online: 31.12.2020

\title{
FACTORS LIMITING QUALITY ASSURANCE PROGRAM IMPLEMENTATION IN FOOD MANUFACTURING COMPANIES IN SHANGHAI, CHINA
}

\author{
Qijun JIANG $^{1}$ (D), Wojciech Jan FLORKOWSKI*2 (D)
}

\begin{abstract}
Address:
${ }^{1}$ Shanghai Ocean University, School of Economics and Management, Huchenghuan Road No 999, Nanhui New City, Pudong District, Shanghai 201306, China

${ }^{2}$ University of Georgia, College of Agricultural and Environmental Sciences, Department of Agricultural and Applied economics, 1109 Experiment Street, 212 Stuckey Building, Griffin, GA 30223-1797, U.S.A.

* Corresponding author's email: wojciech@uga.edu
\end{abstract}

\begin{abstract}
Research background: The motive behind intentional non-microbiological contamination or adulteration of foods is to limit costs, enhance competitiveness, and increase profits. Profits motivate entrepreneurs and costs caused by operating a quality assurance program that is not offset by revenue increases are resisted.

Purpose of the article: To understand the constraints preventing companies from having quality assurance programs, this study examines differences in importance of various constraints in three food industry sub-sectors in Shanghai, China.

Methods: The study applies the own survey data because there is a lack of readily available data on the selected topic. A total of 199 food company representatives completed a questionnaire during a workshop on food regulations between September and December, 2016. Descriptive statistics and the heteroskedasticity corrected regression technique are applied to identify statistically significant factors.

Findings \& Value added: Results show that perishable food sub-sector companies more often agreed that constraints were important in limiting quality assurance programs as compared to the non-perishable food sub-sector. A company anticipating a decrease in revenues in the three years following the survey (2017-2019), employing seasonal workers, and represented by a middle level manager was more likely to view constraints as barriers. Although Shanghai is a large commercially area, the study does not include companies from other provinces recognizing that some regional specificity may matter in implementing quality assurance program. The identified factors suggest the role for government agencies in facilitating such implementation by offsetting selected costs associated with the process of adopting a quality assurance program, while the society at large learns about factors motivating or hampering the implementation of quality assurance programs by food manufacturing companies. This study fills the void in the literature and provides insights about the constraints faced a company generating knowledge for regional and national regulators useful in choosing subsectors and specific aspects facilitating food quality program implementation.
\end{abstract}

Key words: food safety; perishable food sector; non-perishable food sector; external constraint; internal constraint JEL Code: Q13; Q17; Q19

\section{INTRODUCTION}

Food safety issues have plagued the Chinese food industry, causing outbreaks of foodborne diseases affecting domestic and foreign consumers (Zhang et al., 2015). Foodborne illness in China can result from multiple causes. Although Zhang et al. (2015) suggest food microbial contamination is a problem in China, despite under reporting of the incidents (Xue and Zhang, 2013), of particular importance is adulteration of food by adding chemicals (Xiu and Klein, 2010), using additives not intended for use in specific foods (for example, Fairchild et al., 2003), allowing heavy metal contamination (Sun $\boldsymbol{e t}$ al., 2011; Liu et al., 2012; Wang et al., 2019), overuse of allowable substances (Xinhuanet, 2011), or avoiding certain steps in processing. Such contamination may result in chronic foodborne illnesses that develop over a relatively long period in contrast to common microbiological contamination that leads to acute symptoms relatively fast (Xue and Zhang, 2013; Li et al., 2019). The motive behind intentional non-microbiological contamination or adulteration of foods is to limit costs, enhance competitiveness, and increase profits. Profits motivate entrepreneurs and costs caused by operating a quality assurance program that is not offset by revenue increases are resisted. Industry self-policing is an effective and inexpensive way of assuring the implementation of an agreed upon standard (Fairchild et al., 2003), but in China the food manufacturing industry consists mostly of small and medium enterprises (Jin $\boldsymbol{e t}$ al., 2016), creating a polarized structure. This structure slows the emergence of informal institutions that are behind the culture of food safety in developed countries (Liu et al., 2012).

In response to repeated food safety incidents, Chinese government regulators reacted by introducing more stringent and unified rules (Yan, 2010; Yang et al., 2019). 
Although the threat of retribution can possibly reduce food fraud such as adding harmful ingredients (e.g., melamine in dairy products (Pei et al., 2011; Wu et al. 2018; Yang et al., 2020)), they may not encourage implementation of sustained and documented efforts by companies to assure quality of their products. The short-term focus on maintaining economic viability overshadows the benefits of quality assurance as a source of sustained commercial pay-off in the long run.

Recognizing that the commitment of managers is essential for successful quality assurance program implementation in food manufacturing companies, this paper examines opinions concerning constraints preventing companies from having quality assurance programs. Although long-term economic viability can be substantially enhanced by such programs, managers may resist adding costs without clear market signals that such efforts will pay off. The current study uses data collected from food manufacturers located in Shanghai, China, the third largest city in the world (United Nations, 2015). Constraints considered in this study were identified during meetings with company managers and reflect a business rather than consumer or regulator view. The applied survey instrument probed not only for opinions about constraints to the implementation of a quality assurance program, but company and respondent characteristics in search of links that could provide insight to eliminate potential adoption barriers.

Chinese regulators recognize that typical companies are small and their managerial and other resources are limited. Overcoming the reluctance of companies with limited resources may require government assistance to offset some of the costs of implementing a quality assurance program, such as employee training or the cost of designing the program. Widespread public health benefits resulting from reduced risk of acute and chronic foodborne illnesses justify the use of public funds. Agencies entrusted with food safety regulation enforcement can streamline their efforts by learning the constraint $\mathrm{s}$ at the firm level. It is expected that having such programs in food manufacturing companies strengthens the competitive position of firms in domestic and international markets, and prevents food safety incidents.

The geographic scope of the survey is limited to Shanghai, a city that has been experiencing population and income growth. The city's population increased from about 14 million residents in 2000 to 25 million in 2017 and is expected to double to 50 million residents by 2050 (World Population Review, 2017). Shanghai households have the highest consumer expenditure in China, equivalent to $\$ 16,605$ in 2013 , more than three times higher than expenditures in the poorest region of the country. Additionally, the forecasted annual growth in basic food consumption is expected to increase $7.2 \%$ through 2020, while discretionary spending is expected to grow 10.2\% annually (Atsmon and Magni, 2012). The Shanghai area contains highly concentrated purchasing power represented by relatively young, well-educated, and increasingly sophisticated consumers (Hodgson, 2014). Urban residents' food expenditures accounted for $35.8 \%$ of income in China in 2006 (FAO, 2017), and 28\% in
2010, and are expected to decline to $20 \%$ in 2020 (Statista, 2017). Education, income, and lifestyles of Shanghai residents, like Chinese consumers in general, influence consumption patterns and shape preferences for a variety of foods, quality, and safety (Atsmon and Magni, 2012; Kuo, 2017).

\section{LITERATURE REVIEW}

Earlier studies attempted to position food quality assurance in the context of the Corporate Social Responsibility (CSR) concept (Zhang et al., 2015) or by discerning consumer trust of managerial or inspection service expertise (Kim, 2012; Han et al., 2020). The proposed approaches assume that company management will either apply the CSR concept or respond to consumer and establish a process to accommodate expectations of quality assurance. Food companies may employ welleducated quality managers, but they lack the authority and resources available to top management. The common approach to quality assurance is end-of-the-line verification rather than the sustained effort to monitor quality and safety at each processing stage characteristic of the global shift in supplier responsibility for food safety (Trienekens and Zuurbier, 2008). The CSR approach presupposes that a company manager displays actions consistent with the concept in the area of risk management, or that consumers base their trust regarding quality assurance in expertise of managers (Kim, 2012). Either approach is ambiguous with regard to the entrepreneur's profit motive (Guo et al., 2019) and the need to control costs in the price-competitive marketplace.

A company's attitude toward the issue of quality assurance seems to contrast with reported efforts of quality monitoring and control by the government to enhance the national food safety control system (Ni and Zeng, 2009; Jia and Jukes, 2013; Han et al., 2020). Whether change in the institutional environment induces change in company behaviour is arguable. Enforcement of existing regulations may be patchy for a number of reasons. Efforts have focused on regulating processors of aquatic products, meat and meat products, fruits, vegetables, juices, and frozen products containing any of these ingredients destined for export markets (Jin et al., 2016) or on Western consumer perceptions (Lee and Boccalatte, 2019), but the majority of firms supply exclusively domestic customers. Therefore, identifying internal constraints to implementing a quality assurance system as seen from the perspective of managers is a step in eliminating the hurdles. The hurdles could be economic, technical (e.g., require purchase of equipment), or reflect personal attitudes.

A number of studies have investigated Chinese consumer preferences for quality and safety of food (Cheng et al., 2014; Zheng and Rastegari Henneberry, 2009). Because of the vastness of China and its huge population (Holtkamp et al., 2014), most studies focused on urban consumers. Empirical results identified and often quantified the influence of specific factors influencing food preferences, willingness to pay, and purchase decisions. For example, imported pork can effectively compete with domestic pork supplies by adding a food 
safety claim (Ortega et al., 2017). Factors reflect sociodemographic, income and location characteristics. Constructs capturing opinions and cultural beliefs that are difficult to measure have been often applied to broaden insights into consumer attitudes and the process of making consumption choices. For example, consumers trust improved safety if the food was produced under government supervision (Wu et al., 2016; Yang et al., 2019), although self-imposed quality assurance programs could provide a competitive advantage by differentiating the product in a marketplace. Implementation of a quality assurance program offers opportunity to overcome information asymmetry between food companies and customers, otherwise leaving the latter dependent on government inspection services.

\section{DATA AND METHODS}

Studies of company behaviour with regard to the implementation of quality assurance programs are less frequent than studies of consumer quality preferences. The paucity of data exists because systematic data collection is lacking, while efforts to collect data through a single survey are costly. Not only is it difficult to identify companies, but it seems that face-to-face interviews are more acceptable than mail or telephone questionnaires for conducting surveys in China (Zhang et al., 2015). Business surveys require company cooperation, and allocation of time away from managing the firm. Additionally, companies may be asked to share information that in their view compromises their competitive advantage. The attitudes and behaviours of food manufacturing companies may vary across regions (Hodgson, 2014; Holtkamp et al., 2014). Under such circumstances, the response rate from businesses in research surveys is frequently poor. Examples of company survey efforts include using students as trained enumerators to visit food processors (Han et al., 2009; Zhang et al., 2015), but even then the total number of responses may be only 10\% (Han et al., 2009). Surveys of businesses notoriously result in low response rates because they absorb manager time and probe for potentially sensitive information, and lack immediate benefits to the company.

\section{Survey preparation and implementation}

The economic size and commercial and social importance of Shanghai justified its selection for the implementation of a survey probing for constraints in establishing a company-wide quality assurance program. Preparation and design of the survey consisted of several stages. The process was initiated by meeting with a small group of company managers to identify issues related to quality assurance and motives for adopting quality assurance procedures. Insights gained from these discussions were used to prepare specific questions contained in the drafted questionnaire. A draft survey instrument was used in a pilot study to detect potential errors or difficulties in answering questions. Managers in two companies were involved in the pilot study by self-administering the questionnaire to simulate the planned method of implementation. The pilot test did not lead to any changes in the survey instrument. To facilitate response and increase accuracy, a five-point Likert scale allowed choosing an option from "strongly disagree" (1) to "strongly agree" (5), where the middle value (3) captured the neutral stand, i.e., "neither agree nor disagree". Use of the scale to indicate an opinion about an individual constraint enabled the respondent to have a choice and provided flexibility in later estimations in the empirical model.

Company participation in the survey was assured by distributing the questionnaires during a workshop devoted to regulatory issues in the food manufacturing industry. The questionnaire was distributed with the help of the Shanghai Minhang Quality Supervision Bureau and the Shanghai Fengxian Quality Supervision Bureau. Earlier studies reported selecting companies with which a particular institution of higher learning had established relationships as a result of unrelated projects (for example, Zhang et al., 2015). Approaching participants in food safety workshops was very cost effective and generated a high return rate. The survey was conducted between early September and early December 2016. From a total of 244 distributed questionnaires, 199 were completed and returned, yielding an $81.6 \%$ rate of return.

Specific questions pertaining to perceived constraints of implementing a quality assurance program were constructs reflecting different time horizons, issues internal to a company such as organizational aspects of operating a program, management resources, or already having an adequate quality assurance program, and issues accounting for external aspects regarding quality assurance programs. The constraints were grouped into external factors, internal factors, and changes in procedures (Table 1). Although constraints were identified in direct discussions with food company managers, several limitations have been widely recognized in earlier studies. For example, Trienekens and Zuurbier (2008) indicated that a company may reduce quality assurance costs by economies of scale. Size of the company reflects possible economies of scale and large companies are more likely to see benefits of quality assurance programs, but the vast majority of Chinese food companies are classified as small or medium (Jin et al., 2016). The suggested benefits of building a reputation or brand based on a quality assurance system sound rational (Semos and Kontogeorgos, 2007; Trienekens and Zuurbier, 2008), but a company has to invest upfront into the system and cannot prevent competitors from adopting a similar program. Despite studies indicating that many consumers would pay for quality certification and safety assurance, the consensus is that market benefits from having a quality assurance program were not clear. Having a quality assurance program simultaneously imposes record keeping requirements and permanent monitoring (Wang et al., 2009). Training of staff incurs costs and without training and re-training, implementation of a specific quality assurance program may be unsuccessful (Maldonado et al., 2005). Employee retention in a vibrant economy like Shanghai's may pose a challenge and increase training costs, especially if a company employs seasonal workers due to the nature of food product or harvest pattern. 


\section{Estimation approach}

The responses about the constraints in implementing the quality assurance program allowed to create an index as the sum of the selected responses. The specification allowed for the use of the OLS regression, but as a precaution against the possibility of heteroscedasticity, the applied methods was the heteroscedasticity-corrected OLS (Gujarati, 2003). The method generally generates the same size of the coefficients, but the adjusted standard errors affect the statistical significance. Consequently, the estimation results are more accurate than without the correction.

\section{RESULTS AND DISCUSSION}

\section{Firm characteristics}

The reported range of revenue was substantial but average revenues suggest that the majority of firms were small or medium in size. Respondents provided figures for revenues for 2015, the calendar year proceeding the year of the survey. The average revenues were nearly 87 million yuan-renimbi (or about $\$ 12.528$ million at the exchange rate of $\$ 1=6.9447$ yuan-renimbi recorded on January 1, 2017; (XE Currency Converter, 2017)).

An average firm employed about 141 individuals. Similar to results regarding total 2015 revenues, some firms appear to be quite small, while the largest firm reported nearly 4800 workers, causing the average number of employees to be high. Besides full-time employees, firms may hire part-time workers as determined by the needs of handling, processing, and shipping operations. Part-time employment may also help control costs. Among various forms of employment, 53 firms indicated having part-time year-round employees. An average firm had a total of about 17 year-round part-time employees with the largest number of this type of job being 261 persons. The need for part-time workers varies widely across companies. Food manufacturing is affected by seasonality of available raw material for processing and some plants may adjust their employment according to the season. An average firm (of 60 firms reporting seasonal workers) employed about 63 persons on a full-time basis as seasonal workers. Another 21 firms stated they employed part-time workers on a seasonal basis, with the average firm employing about 21 workers. Part-time seasonal employees present a challenge because their training demands company resources, but trained workers may not return to the company next season. In a fastgrowing metropolitan area like Shanghai, finding another job is easy, thus requiring a company to spend resources on training new seasonal hires every year, thereby adding costs.

For $62 \%$ of firms, sales in the regional Shanghai market accounted for more than one half of total sales. Only $26 \%$ of firms reported sales in excess of $51 \%$ to other regional markets, while export market sales are of marginal importance despite Shanghai being a center of international commerce. Clearly, the food manufacturing firms surveyed in the area are oriented toward the domestic market, coinciding with observed figures regarding the number of employed workers. Domestic orientation stresses the importance of domestic and regional consumer preferences but with increasing consumer interest in food safety, having a quality assurance program seems highly desirable.

An important factor that potentially motivates adoption of improvements is expectations with regard to company performance in the near future. Companies were asked about forecast revenues for the three years following the survey. The majority of food manufacturing companies, $69 \%$, expect their revenues to increase in the three years following the survey, i.e., 2017-2019. Only $8 \%$ of firms expected their revenues to decline. The very optimistic expectations correspond to the forecasted growth of discretionary income and rising expenditures on food among Shanghai residents. Whether the anticipated positive developments encourage the adoption of a quality assurance program by a company to secure continued growth and improved competitiveness remains to be seen.

\section{Respondent characteristics}

In the current survey, $45 \%$ of respondents were males and nearly 37 years old on average (Table 2). The average education score is 2.45 , suggesting that the education level fell somewhere between junior college and a college undergraduate degree. The most common position occupied was classified as "middle management" (Table 2 ). Although the period of working for the company ranged from less than a year to 35 years (Table 2), the average respondent had been with a given company only about 6.5 years. The length of employment with the company corresponds to the average age of a respondent, suggesting that many respondents were at the beginning of their professional careers. Not surprisingly, the age and education level of respondents corresponds well to the dominant group of consumers in Shanghai, who are generally not older than 35 years and college-educated.

\section{Quality assurance constraints}

The set of 12 constraints was grouped into external factors, internal factors, and change in procedures. The questions probing for opinions about specific constraints allowed respondents to choose from among five options: from $1=$ strongly disagree to $5=$ strongly agree. The uneven scale included the middle option reflecting a neutral opinion regarding the issue (Table 1 ).

Respondent s of each external constraint show large differences across three food subsectors. The largest percentage of respondents agreed that external factors constraining implementation of quality assurance programs were most evident in the perishable food subsector. In particular, short-term implementation costs were viewed as a constraint. In contrast, $46 \%$ and $50 \%$ of non-perishable food manufacturing firms disagreed that the short- and long-term costs constrained the implementation of quality assurance programs. Among other food manufacturing companies, a large proportion lacked an opinion about the long-term costs as limiting quality assurance program adoption. An important issue is that while the market rewards companies having quality assurance programs, results show that a relatively large percentage of firms in the perishable food subsector and other food subsectors feel that such rewards are unclear. This directly contradicts studies reporting that consumers 
show preference for food safety and quality, and implies that although consumers may express such preferences, their purchase choices have not been clearly communicated to food processors. Under such circumstances, companies may feel the regulatory pressure to assure quality, but are not able to use quality assurance programs to enhance their reputation and compete in the marketplace. If loss of reputation is unlikely, company interest in implementing a quality assurance program is weak (Liu et al., 2012).

Six constraints were classified as internal factors potentially limiting the implementation of quality assurance programs. Company size was viewed as a constraint by $40 \%$ of other food manufacturers and $48 \%$ of perishable food processors. Interestingly, the smallest percentage of respondents agreed that lack of time on the part of management was a constraint (Table 1). If managers are not limited in their time, other constraints are relatively more important and should be targeted to encourage quality assurance program adoption. Moreover, a relatively small share of perishable food manufacturers agrees (26\%) that they lack knowledge of alternative quality assurance systems. The corresponding share of respondents from non-perishable food companies and other food manufacturers is also relatively small, $31 \%$ and $30 \%$, respectively. The lack of competent consultants capable of advising on quality assurance program implementation is noted by $52 \%$ by respondents from the perishable food subsector, about twice as many as from the other two subsectors (Table 1). This clearly reveals the type of company that may require outside help in learning where to find the expertise needed to implement a quality assurance program, likely because handling perishable foods poses specific challenges compared to nonperishable foods. The lack of competent consultants as a constraint in perishable food companies is supported by the very low percentage (19\%) of companies agreeing that their current food safety control system is sufficient. Indeed, respondents representing the other two subsectors also seldom agree that their current food safety control is adequate (Table 1). Responses to the statement that benefits of a quality assurance system are unclear are consistent with the observed response pattern observed for the two previously discussed constraints. Namely, only $19 \%$ of respondents from the perishable food subsector agree that benefits from having a quality assurance program are unclear, while the corresponding shares of respondents in the non-perishable food and other food subsectors are $24 \%$ and $30 \%$, respectively. Overall, it appears that the responding companies recognize the benefits, but tend to lack knowledge about available alternative quality assurance systems and where to find reliable advisors to implement a program.

Among constraints classified as "changes in procedures," a relatively large share of respondents from each subsector category disagree that the requirement for additional record keeping is a constraint. However, the cost of permanently managing a quality assurance program is viewed as constraining by $38 \%$ of respondents from the other food manufacturing subsector, $41 \%$ of respondents from non-perishable food subsector, and $48 \%$ of respondents from the perishable food subsector. The most important constraint among "changes in procedures" is the need for additional staff training associated with implementation of a quality assurance program. Nearly identical shares of respondents from other food manufacturing subsector and non-perishable food subsector, $44 \%$ and $43 \%$, respectively, contrasts with $67 \%$ of respondents representing the perishable food companies that view the requirement of additional staff training as limiting.

Overall, the perishable food subsector views several of the constraints differently than did the other two food subsectors. Among the external factors, two economically important constraints (short- and long-term implementation costs) causes concern in the perishable food subsector, while among internal factors the lack of knowledgeable consultants is viewed as a significant limitation. Changes in procedures of particular concern to the perishable food industry are the cost of permanently managing the quality assurance system and staff training. Concerns about those two constraints are also shared by respondents from the non-perishable food subsector. The other food manufacturing subsector expressed the most concern about the need for additional staff training and two internal factors, i.e., unclear benefits of having a quality assurance system and size of the company, suggest possible resource constraints and an opportunity for assistance from regulators to adopt a suitable quality assurance program.

\section{Regression analysis}

Responses regarding the 12 constraints were summed, creating an index. The sum is between 12 and 60 as the five steps in the response scale measuring the degree of agreement with each listed constraint ranged from $1=$ strongly disagree to $5=$ strongly agree. The higher the sum, the more often a respondent representing the company agreed that a stated constraint hampered implementation of a quality assurance program. The sum was converted into an index ranging from 1 to 100 , where a sum of 12 (respondent "strongly disagreed" that any statement constrained the implementation of a quality assurance program) was lower boundary of 1 , and a sum of 60 meant a respondent "strongly agreed" that constraint mattered, was the maximum index value.

Estimation results of the heteroscedasticity-corrected OLS are shown in Table 3. The overall fit shows the partial explanatory power of the equation, reflecting the complexity of the issue at hand, including the heterogeneity of the food manufacturing industry. The goodness-of-fit measures are $\mathrm{F}=3.02$ at $\mathrm{p}<0.0015$ and the adjusted $\mathrm{R}$ square is 0.1010 . The latter tends to be smaller in the case of cross-sectional data such as those used in the current study compared to time-series data. Four variables in addition to the constant are statistically significant and provide interesting insights into factors associated with the listed constraints as obstacles in implementing a quality assurance program.

It was hypothesized that the constraints may vary among food companies primarily as a result of the perishability of raw material. For example, a seafood processor faces different risks of product safety than a noodle manufacturer. 


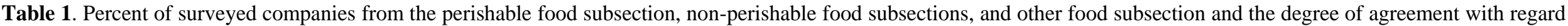
to 12 constraints preventing quality assurance program adoption.

\begin{tabular}{|c|c|c|c|c|c|c|c|c|c|c|}
\hline \multirow[t]{2}{*}{ Constraint } & \multicolumn{3}{|c|}{ Other food subsect } & \multicolumn{3}{|c|}{ Non-perishable food subsect } & \multicolumn{4}{|c|}{ Perishable food subsect } \\
\hline & Disagree & $\begin{array}{l}\text { Neither agree nor } \\
\text { disagree }\end{array}$ & Agree & Disagree & $\begin{array}{l}\text { Neither agree nor } \\
\text { disagree }\end{array}$ & Agree & Disagree & $\begin{array}{l}\text { Neither agree nor } \\
\text { disagree }\end{array}$ & Agree & \\
\hline External factors & & & & & & & & & & \\
\hline $\begin{array}{l}\text { Cost of implementation in the } \\
\text { short run }\end{array}$ & 33 & 34 & 33 & 46 & 34 & 20 & 11 & 37 & & 52 \\
\hline $\begin{array}{l}\text { Cost of implementation in the } \\
\text { long run }\end{array}$ & 36 & 42 & 22 & 50 & 27 & 23 & 26 & 26 & & 48 \\
\hline $\begin{array}{l}\text { Lack of clear rewards in the } \\
\text { market for having a quality } \\
\text { assurance system } \\
\text { Internal factors }\end{array}$ & 37 & 23 & 40 & 38 & 33 & 29 & 33 & 30 & & 37 \\
\hline Size of company & 27 & 33 & 40 & 46 & 21 & 33 & 26 & 26 & & 48 \\
\hline $\begin{array}{l}\text { Lack of time on the part of } \\
\text { management }\end{array}$ & 44 & 29 & 27 & 52 & 20 & 28 & 33 & 37 & & 30 \\
\hline $\begin{array}{l}\text { Lack of knowledge about } \\
\text { advantages and disadvantages of } \\
\text { alternative quality assurance } \\
\text { systems }\end{array}$ & 44 & 26 & 30 & 44 & 24 & 31 & 37 & 37 & & 26 \\
\hline $\begin{array}{l}\text { Lack of competent consultants to } \\
\text { advise about the implementation } \\
\text { of a quality assurance program }\end{array}$ & 36 & 36 & 29 & 34 & 40 & 26 & 15 & 33 & & 52 \\
\hline $\begin{array}{l}\text { Current food safety control system } \\
\text { is sufficient }\end{array}$ & 38 & 40 & 22 & 41 & 31 & 28 & 33 & 48 & & 19 \\
\hline $\begin{array}{l}\text { Unclear benefits of having a } \\
\text { quality assurance system } \\
\text { Change in procedures }\end{array}$ & 45 & 25 & 30 & 43 & 32 & 24 & 26 & 56 & & 19 \\
\hline $\begin{array}{l}\text { Requirement of additional record } \\
\text { keeping }\end{array}$ & 47 & 19 & 34 & 47 & 32 & 21 & 37 & 37 & & 26 \\
\hline $\begin{array}{l}\text { Cost of managing the quality } \\
\text { assurance system permanently }\end{array}$ & 29 & 33 & 38 & 33 & 26 & 41 & 19 & 33 & & 48 \\
\hline $\begin{array}{l}\text { Additional training requirements } \\
\text { for the staff }\end{array}$ & 30 & 26 & 44 & 28 & 29 & 43 & 19 & 15 & & 67 \\
\hline
\end{tabular}


Three subsectors of the food manufacturing industry (i.e., perishable food, non-perishable food, and "other" food subsectors) present differences associated with the type of raw material handled and different regulatory approaches to assuring safety perishable foods. Specifically, companies producing meat and meat products, dairy products, fresh fruits and vegetables, and seafood are required to comply with practices not imposed on nonperishable food companies. The test on differences among mean values of the indices for each of the subsectors, i.e., perishable, non-perishable, and other food companies, indicated a statistical difference (at $\mathrm{p}<=0.05$ ) between the perishable food sub-sector and the other two subsectors. Subsequent regression analysis includes a binary variable indicating only companies classified as handling perishable food to account for possible differences in constraints limiting the implementation of a quality assurance program. This binary variable is statistically significant (Table 3), suggesting that respondents from perishable food subsector companies perceived the constraints differently and, specifically, they were likely to agree more often with their effect than were those from companies in other subsectors.

Not surprisingly, companies that admitted they expected their revenues to decrease in the three years following the survey were more likely to have a high value of index. It is plausible that the anticipation of shrinking revenues was an overwhelming constraint preventing commitment of company resources to implement a quality assurance program. The survey did not probe for possible reasons behind such expectations, but it may be that such companies were already unable to effectively compete in the market place and likely to limit their presence.

Among company employment measures, the binary variable indicating the use of seasonal workers was associated with the high value of the index. Highly seasonal production may imply that a company operates only for a period of time each calendar year, and the pool of permanent employees was small. Hiring seasonal employees meant that each worker could be viewed as posing a relatively higher risk to food safety and had to be thoroughly trained or re-trained in procedures consistent with the implemented quality assurance program. Any such intense training absorbs company resources.

Respondent characteristics were also included in the specified relationship and served as the basis to create the following variables: length of time working at the business (a binary variable indicating a period of no more than 5 years), being a member of middle or upper management, and respondent's age. Interestingly, those in the position of middle management were more likely to perceive the presented constraints as limiting quality assurance program implementation than were employees in other positions. It is quite likely that middle level managers would be responsible for implementing and monitoring the program, maintaining records, and training staff. Being the closest to the actual production process, middle level managers visualized the extent of tasks involved not only during the implementation but also subsequent operation of a quality assurance program. Additionally, they would most likely be directly responsible for any failures compromising food safety.

Table 2. Descriptive statistics of companies and respondent characteristics in the survey of food manufacturing industries in Shanghai, China in 2016.

\begin{tabular}{lrrrr}
\hline Variable name & Mean & \multicolumn{1}{l}{ Std. dev. } & Min & Max \\
\hline Revenues in 2015 & 86487982.55 & 297322883 & 22.47 & 3000000000 \\
Total number of full-time employees & 142 & 430 & 4 & 4795 \\
Number of part time year-round employees & 17 & 39 & 1 & 261 \\
Number of full-time seasonal employees & 63 & 106 & 5 & 600 \\
Number of part-time seasonal employees & 21 & 47 & 1 & 222 \\
Age & 37 & 7 & 22 & 60 \\
Gender & 124 & 270 & 4 & 2678 \\
Education & 2 & 1 & 1 & 4 \\
Years with the company & 6 & 6 & 1 & 35 \\
\hline
\end{tabular}

Table 3. Heteroscedasticity corrected OLS proportional regression results of the equation modelling measurement of constraints in quality assurance program implementation by food manufacturing companies in Shanghai, China.

\begin{tabular}{lrrrr}
\hline Variable name & Coefficient & Std. error & t-value & p-value \\
\hline Intercept & $35.80191^{\mathrm{a}}$ & 7.1048 & 5.04 & $<.0001$ \\
Company size 1 & 3.24242 & 2.8280 & 1.15 & 0.2532 \\
Company size 2 & 4.02436 & 3.1332 & 1.28 & 0.2007 \\
Number of employees & -3.97921 & 3.0463 & -1.31 & 0.1932 \\
Employs seasonal workers & $4.56559^{\mathrm{a}}$ & 2.4094 & 1.89 & 0.0598 \\
Years respondent with the company & 4.50685 & 2.8331 & 1.59 & 0.1135 \\
Middle management & $5.57491^{\mathrm{a}}$ & 2.8565 & 1.95 & 0.0526 \\
Upper management & 4.69082 & 3.8006 & 1.23 & 0.2188 \\
Perishable food industry subsector & $8.63364^{\mathrm{a}}$ & 2.3279 & 3.71 & 0.0003 \\
Expect sales decrease in the next 3 years & $10.83076^{\mathrm{a}}$ & 2.6948 & 4.02 & $<.0001$ \\
Respondent's age & -0.20919 & 0.1630 & -1.28 & 0.2012 \\
\hline
\end{tabular}

Note: ${ }^{\text {a }}$ Significant at $\alpha=0.10$. 


\section{CONCLUSIONS AND IMPLICATIONS}

Food safety incidents in China has led to regulatory changes and increased consumer awareness, yet the key to implementing quality assurance programs rests with company management. This study focused on issues surrounding food safety and quality risks, proposed solutions, benefits of comprehensive safety programs, and consumer preferences for safe food by investigating the constraints to quality assurance program implementation among food manufacturing companies in Shanghai. The lack of information about constraints and their importance required collecting of data through a survey of company representatives at workshops devoted to industry regulations. Improving the understanding of company perspectives regarding constraints is essential to design effective ways of adopting successful quality assurance programs.

In this study, we identified 12 constraints and classified them into three groups through a discussion with several food company managers. Furthermore, recognizing the diversity of processed foods, companies were categorized according to the type of food they processed, i.e., perishable food subsector, non-perishable food subsector, and other (unidentified) food sub-sector. Each subsector showed some differences in constraints, but statistical tests confirmed significant differences between the perishable food subsector and the other two subsectors. The former included companies processing meat, dairy, seafood, and fresh fruit and vegetable products. This result likely reflects $\mathrm{s}$ of food manufacturing companies across China and even other countries.

The measures of agreement regarding each constraint were summed for every respondent to create an index. Higher index values indicated stronger recognition of constraints as obstacles to implementing a quality assurance program. The index was regressed on company and respondent characteristics to identify possible factors associated with its high value. Statistically significant variables provide a reference to overcome s preventing implementation of quality assurance programs. Results confirmed a difference in s between the perishable food subsector and other food manufacturing companies. Clearly, perishable food processors face a complex set safety risks to their products stemming from the nature of raw materials and the required handling to protect quality as well as a very narrow marketing window. Given the heterogeneity of perishable foods, assisting this subsector in designing and implementing quality assurance programs, and the necessary staff training, poses a challenge. Such challenges have been overcome in other countries, but a specifically Chinese situation is the dominance of small and very small companies. The size of companies likely limits resources that can be used, suggesting a need for governmental assistance. Central and provincial governments may consider absorbing the costs of designing programs, given specific characteristics of raw and processed products, e.g., meats, seafood, fruits, or vegetables. The assistance may be provided free of charge or require repayment proportional to total annual revenues. Micro and small companies could then expect to benefit relatively more than large- scale firms.

Since assistance cannot reach all companies immediately, the order in which companies are assisted needs to be considered. Results of this study show that companies expecting declining revenues viewed constraints more seriously than those anticipating growth or no change in revenues. For example, choosing companies showing rapid growth in revenues may enhance their competitiveness and consumer preference for products. Nevertheless, in the case of some companies with declining revenues assistance may be helpful if these firms supply food products of special importance.

Another criterion for selecting companies for funding with developing quality assurance programs may be those employing seasonal workers. Regression results indicate that having seasonal workers increased the constraints as preventing quality assurance program implementation. Yet, seasonal food products are highly sought by consumers. Seasonal supplies of specific foods with their associated high demand are particularly vulnerable because any incident which results in demand contraction can mean a substantial loss of revenues, putting the economic existence of a company at risk. By absorbing all or some seasonal worker training costs, a government agency can provide effective help to a company. Such assistance can be provided for a defined period, for example three seasons, until the company implements the necessary procedures, but also to avoid criticism of favouring any particular subsector. It is possible that initial assistance may be administered by public health agencies motivated by the need to address a potentially large threat to consumers, evidenced by recent incidents of foodborne illness.

The study's limitation is its narrow geographical focus. However, organization of a survey with a larger regional or national scope would require substantial resources and preparation time. Moreover, constraints reflect those identified by a small number of managers and some important issues might have been omitted. A future study may revise the list of constraints and involve top managers of companies, who have the authority to make decisions about implementing quality assurance programs, or focus only on micro-companies to examine size-specific quality assurance issues and search for effective solutions.

\section{REFERENCES}

ATSMON, S., \& MAGNI, M. (2012). Meet the Chinese consumer 2020. McKinsey \& Company. available at: http://www.mckinsey.com/global-themes/asiapacific/meet-the-chinese-cosnumer-of-2020

CHENG, L., YIN, C., \& CHIEN, H. (2014). Demand for milk quantity and safety in urban China: evidence from Beijing and Harbin, Australian Journal of Agricultural and Resource Economics, 59(2), 275-287. https://doi.org/10.1111/1467-8489.12065

FAO. (2017). Food consumption expenditure. available at: www.fao.org/fileadmin/templates/ess/documents/foo d.../ShareOfFood_en.xls. 
FAIRCHILD, G. F., NICHOLS, J. P., \& CAPPS, O. JR. (2003). Observations on economic adulteration of high-value food products: the honey case. Journal of Food Distribution Research 34(2), 38-45. 10.22004/ag.econ.27319

GUJARATI, D. N. (2003). Basic Econometrics. New York: McGrew-Hill/Irwin.

GUO, Z., BAI, L., \& GONG, S. (2019). Government regulations and voluntary certifications in food safety in China; A review. Trends in Science \& Technology, 90 ,

160-165.

https://doi.org/10.1016/j.tifs.2019.04.014

HAN, G., YAN, S., \& FAN, B. (2020). Regional Regulations and Public Safety Perceptions of Qualityof-Life Issues: Empirical Study on Food Safety in China. Healthcare, 8(3),

275. https://doi.org/10.3390/healthcare8030275

HAN, J., TRIENEKENS, J. H., \& OMTA, W. W. F. (2009). Integrated information and logistics management, quality management and firm performance of pork processing industry in China. British Food Journal 111(1), 9-25. https://doi.org/10.1108/00070700910924209

HODGSON, A. (2014). Income and expenditure in China: understanding regional disparities to unleash market potential. http://blog.euromonitor.com/author/anhodgson

HOLTKAMP, N., LIU, P., \& MCGUIRE, W. (2014). Regional patterns of food safety in China: What can we learn from media data? China Economic Review 30 , 59-468. https://doi.org/10.1016/j.chieco.2014.07.003

JIA, C., \& JUKES, D. (2013). The national food safety control system of China - A systematic review. Food Control. 32(1), 236-245. https://doi.org/10.1016/j.foodcont.2012.11.042

JIN, S., GUO, H., MAO, F., ZHOU, L., \& CHENG, G. (2016). Willingness to pay for implementing HACCP systems in China's small and medium-sized food enterprises. International Journal of Food and Agricultural Economics 4(2), 25-38. 10.22004/ag.econ.234908

KIM, R. B. (2012). Consumers' s of food risk management quality: Chinese and Korean evaluations. Agricultural Economics - CZECH, 58(1), 11-20. https://doi.org/10.17221/178/2010-AGRICECON

KUO, Y. (2017). 3 great forces changing China's consumer market. World Economic Forum on Latin America 2017. https://www.weforum.org/agenda/216/01/3-great-forces-changing-chinas-consumermarket/, Accessed April 7, 2017.

LI, Y., PEI X., YAN, J., LIU, D., ZHNAG, H., YU, B., LI, N., \& YANG, D. (2019). Prevalence of foodborne pathogens isolated from retail freshwater fish and shellfish in China. Food Control, 99, 131-136. https://doi.org/10.1016/j.foodcont.2018.12.024

LIU, H., KERR, W. A., \& HOBBS, J. E. (2012). A review of Chinese food safety strategies implemented after several food safety incidents involving export of Chinese aquatic products. British Food Journal, 114(3), 372-386.
LEE, H. F., \& BOCCALATTE, M. (2019). Food safety in China from North American and European perspectives, Asian Geographer, 36(2), 143-164, https://doi.org/10.1080/10225706.2018.1527237

MALDONADO, E., HENSON, S., CASWELL, J., LEOS, L., MARTINEZ, P., ARANDA, G., \& CADENA, J. (2005). Cost-benefit analysis of HACCP implementation in the Mexican meat industry. Food Control 16(4), 375-381. https://doi.org/10.1016/j.foodcont.2004.03.017

NI, HG., \& ZENG, H. (2009). Law enforcement is key to China's food safety. Environmental Pollution 157(7), 1990-1992. DOI: 10.1016/j.envpol.2009.02.002

ORTEGA, D. L., CHEN, M., WANG, H. H., \& SHIMOKAWA, S. (2017). Emerging markets for U.S. pork in China: experimental evidence from mainland and Hong Kong consumers. Journal of Agricultural and Resource Economics, 42(2). 275-290. 10.22004/ag.econ.258002

PEI, X., TANDON, A., ALLDRICK, A., GIORGI, L., HUANG, W., \& YANG, R. (2011). The China melamine milk scandal and its implications for food safety regulation. Food Policy. 36(3), 412-420. https://doi.org/10.1016/j.foodpol.2011.03.008

SEMOS, A. \& KONTOGEORGOS, A. (2007). HACCP implementation in northern Greece: food companies' perception of costs and benefits. British Food Journal. 109(1), 5-19.

SUN, J. F., WANG, C. N., WU, Y. N., YUAN, B. J., TIAN, Z. H., SONG, X. Y., LI, C. Y., \& LIU, P. (2011). Long term dietary exposure to lead of the population of Jiangsu Province, China. Food Additives and Contaminants Part A-Chemistry Analysis Control Exposure \& Risk Assessment. 28(1),107-114. https://doi.org/10.1080/19440049.2010.533290

TRIENEKENS, J., \& ZUURBIER, P. (2008). Quality and safety standards in the food industry, developments and challenges. International Journal of Production Economics. 113(1), 107-122. https://doi.org/10.1016/j.ijpe.2007.02.050

UNITED NATIONS. (2015). World urbanization prospects - the 2014 revisions. Department of Economics and Social Affairs. Population Division. ST/ESA/SER.A/366.

STATISTA (2017). Annual per capita consumption expenditure in China. www.statista.com/statistics/278699/annual-percapita-consumption-expenditure-in-china/

WANG, M., LIANG, B., ZHANG, W., CHEN, K., ZHANG, Y., ZHOU, H., CHENG, Y., LIU, H., ZHONG, X., LI, Y., \& LIU, Y. (2019). Dietary Lead Exposure and Associated Health Risks in Guangzhou, China. International Journal of Environmental Research and Public Health, 16(8), 1417. https://doi.org/10.3390/ijerph16081417

WANG, Z., YUAN, H., \& GALE, F. (2009). Costs of adopting a hazard analysis critical control point system: Case study of a Chinese poultry processing firm. Review of Agricultural Economics, 31(3), 574588. 10.1111/j.1467-9353.2009.01454.X https://doi.org/10.1108/00070701211213474 
World Population Review, Shanghai population 2017. http://worldpopulationreview.com/worldcities/shanghai-population/

WU, L., WANG, H., ZHU, D., HU, W., \& WANG, S. (2016). Chinese consumers' willingness to pay for pork traceability information-the case of Wuxi. Agricultural Economics, 47(1), 71-79. https://doi.org/10.1111/agec.12210

WU, X., LU, Y., XU, H., LV, M., HU, D., HE, Z., LIU, L., WANG, Z., \& FENG, Y. (2018). Challenges to improve the safety dairy products in China. Trends in Food Science \& Technology, 76, 6-14.

XE CURRENCY CONVERTER. (2017). http://www.xe.com/currencyconverter/convert/?Amo $\underline{\text { unt }=1 \& \text { From }=\text { USD\&To }=\mathrm{CNY} \text { Accessed } 1 \text { April }}$ 2017.

XUE, J., \& ZHANG, W. (2013). Understanding China's food safety problem: an analysis of 2387 incidents of acute foodborne illness. Food Control, 30(1), 311-317. https://doi.org/10.1016/j.foodcont.2012.07.024

XINHUANET, (2011). Ministry of Agriculture sends delegations to investigate the use of clenbuterol in animal food production in Henan Province.

XIU, C., \& KLEIN, K. K. (2010). Melamine in milk products in China: examining the factors that let to deliberate use of the contaminant. Food Policy 35(5), 463-470.

https://doi.org/10.1016/j.foodpol.2010.05.001
YAN, H. N. (2010). The reform of the Chinese regulatory system for food safety. Academic Research, 5, 43-52.

ZHANG, D., GAO, Y., \& MORSE, S. (2015). Corporate social responsibility and food risk management in China: a management perspective. Food Control, 49, 2-10. https://doi.org/10.1016/j.foodcont.2013.01.030

YANG, L., ZHU, J., HUANG, Z., \& GENG, J. (2019). A systematic review of China's food safety management since reform and opening up. Emerging Markets Finance and Trade, 55(15), 3472-3489, https://doi.org/10.1080/1540496X.2019.1642194

YANG, Y., HUISMAN, W., HETTINGA, K. A., ZHANG, L., \& VAN RUTH, S. M. (2020). The Chinese milk supply chain: A fraud perspective. Food Control, 113, 107211. https://doi.org/10.1016/j.foodcont.2020.107211

ZHENG, Z., \& RASTEGARI HENNEBERRY, S. (2009). An analysis of food demand in China: a case study of urban household in Jiangsu Province. Review of Agricultural Economics 31(4), 873-893. 10.1111/j.1467-9353.2009.01471.x 